\title{
BH678: Big History in the Italian Middle Schools: A Manifesto against the Fragmentation of Knowledge
}

\author{
Paolo Vismara \\ Scuola Secondaria di Primo Grado"Segantini”, Nova Milanese, Italy
}

Correspondence I Paolo Vismara, paovisma@gmail.com

Citation I Vismara, Paolo. 2020. “BH678: Big History in the Italian Middle Schools: A Manifesto against the Fragmentation of

Knowledge." Journal of Big History 4 (3): 97-101.

DOI I https://doi.org/10.22339.jbh.v4i3.4350

\section{K E Y W O R D S}

Big History

Middle School

Personal Growth

Spiritual Growth

scenius

thresholds

\section{A B S T R A C T}

With the Big History Italia BH678 Project I have introduced the Big History approach in the Italian middle schools, proposing an interpretation of the history of the universe as a way of creating a complex fusion among the sciences and a symbolic path for personal and spiritual growth. Starting from a deep love for complexity, I have written a novel, Storia interiore dell'Universo (now in print for the Italian market), that brings Big History into a poetic and psychedelic landscape. If you want to know the universe, probably, sometimes your body, your brain, your matter are enough; but if you desire to learn from the universe and you work in education, you should consider the whole Homo sapiens, as I believe our species learns only through feeling. Each Big History threshold is an opportunity to feel the echo of some keywords that contribute to developing our Inner Big History, taking off from apparently outer island-moments scattered across spacetime.
Lacking an invitation, education must invite itself to the table of the branches of knowledge, a fascinating research laboratory aimed at interpreting contemporaneity. Here voices harmonize. There is no arrogance in formulating hypotheses because this type of education searches for objective results in the ultimate investigation, that of increasing the quality of life of our species, acting on the reality of the present in order to help us be happy with that of the future. There, seated, vibrant, are the voices of a desire to be an expression created by change. Education listens, aware of being able to learn from the whispers of each different cultural perspective.

Assuming we agree that the nature of reality is a system of complex systems, the proposed BH678 format is configured as a theory of surgical reduction of the gap existing between the complex extra-scholastic reality and the alienating scholastic reality. The disturbing introduction of these categories appears necessary for only the

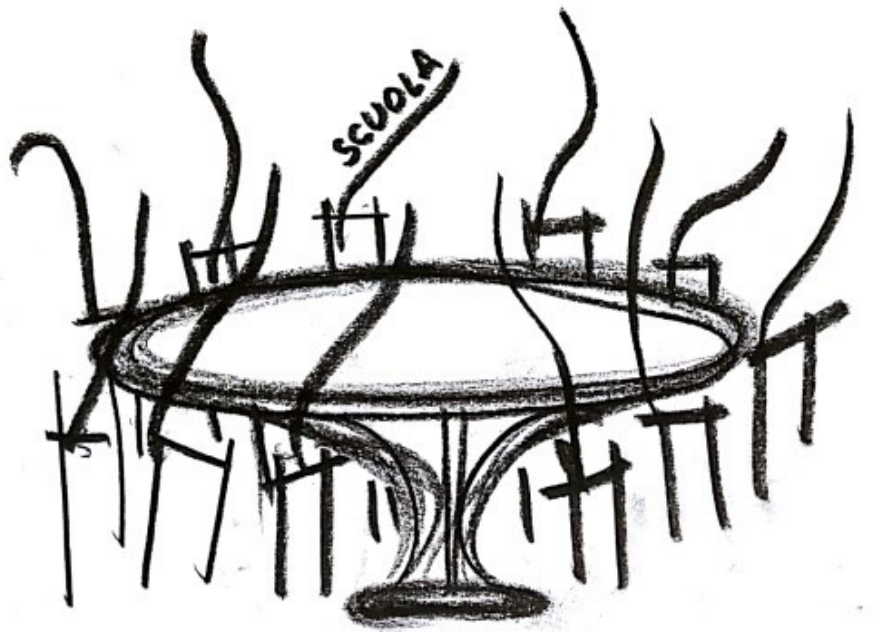

Figure 1 Education

love of horror as soon as you look closely at middle school. It often presents itself as a shattered and bureaucratically articulated sequence of fragmenting fragments and fragmenting institutions-a diabolical device capable of perfectly representing the opposite of a complex system, 
the opposite of reality. Follow the rhythm, the repetition, the delineated form of the fragments of knowledge, fragments of time, fragments of space, fragments of the mind. At school we have fragmented entities for knowledge, fragmented entities in charge of time, fragmented entities for physical spaces and fragmented entities that act on the minds of its occupants-a complete service, served up in apparently reassuring packages that are sadly hermetically sealed. An educational offering of this kind would be perfect if our goal were to create students hemmed in by schizophrenia and serial fetishism, moving from one subject to the next. In fact, the unfortunate pupils, in order to survive and indeed to make a good impression in the eyes of the scholastic system, now must: construct an entirely different image of reality with respect to extra-scholastic complexity; constantly confuse the detail with the whole during each boxed lesson experience; and finally demonstrate the ability to repeat $N$ times the manifestations of their love for each hermetic fragment, observing the seriality that the system expects. In this organization there are no structured moments in which to take notice of the existence of a global and complex tableau. It is not like this at the table of knowledge, and education realizes it. Despite this bleak practice, fortunately, reality imposes itself with its own complex, embracing nature, and therefore the artistteachers cannot resign themselves to postfragmentation.

In the commitment to fight fragmentation, the BH678 format has been identified as a tool that operates on three levels: a physical level, a mental level, and a curricular didactic level. These levels are nothing but different variations on the concept of architecture, and it is possible to consider the first two levels as preliminary to the curricular didactic plan that the present work intends to deepen. However, our idle talk becomes inspiring when it takes care of the common denominator of the three levels of the anti-fragmentation intervention. The minds of many teachers, school buildings and the school curriculum are characterized by the cumbersome presence of walls, divisions, and fragmented entities. Despite some excellent ministerial suggestions, the three archi- tectural levels in question reflect the fearful attitude that has brought up generations of students in the privation of complexity, and that appears happy to preserve itself within the defined traditional regulations. $\mathrm{BH} 678$ proposes, instead as a visionary of the lowest common denominator, a model inspired by a ring surrounding a group of towers-no, skyscrapers, students reaching toward the sky.

The primary requirement is to create and preserve an empty space in the center of the mind, of the buildings, of the curriculum. The hole in the center of the ring is redeeming; it is the space in which the possibility of seeing all the skyscraper students climb toward the infinite becomes a reality. Oh yes, they all stretch upward, but each in their own way. Perhaps, this is what fascinates the skyscraper-Homo sapiens, the personalization

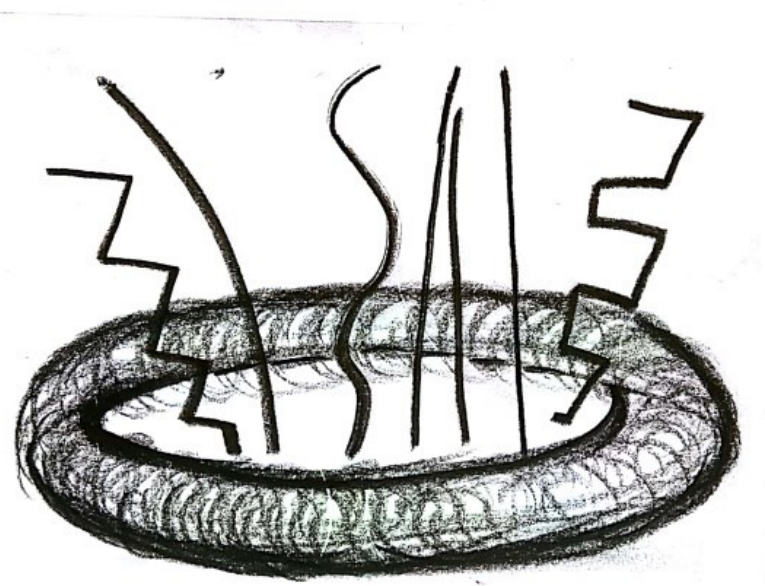

Figure 2. School

of the ascent. Many of these buildings have forgotten the very idea of open space, or maybe they have never experienced it. Many teachers' minds have forgotten the all-consuming pleasure of being fully rounded cultural beings, or perhaps they have never enjoyed the pleasure of themselves outside the disciplinary boundaries. At the table, however, this sensation is felt in the branches. Only in the empty space do the students experience the possibility of being autonomous actors of their own path of growth and education. Freedom of choice in the organized empty space, creative responsibility. Familiarity with the artistic, experimental work of research. Delusions in the minds of many fragmented school heads and teachers. The essence of metamorphosis needed 
for middle school. I have removed partition walls, created open spaces, transparent gathering places in which to bring together the fragments of teachers' minds. The physical and mental reality are only one thing, and only by passing from the walls of the classrooms to the emptiness of the corridors and the recovered spaces is the slavery of comfortable fragmented entities removed from the teachers, and they are brought into the space of the breath of creation.

Here it is, ethereal, the substratum of a good learning environment: a complex and fascinating entity, but incomplete if designed for only students. BH678 is designed for Homo sapiens, not for students. The first to be immersed, overturned and deconstructed by the learning environment must be the teachers, who, enjoying the emptiness, will experience such exaltation that they will radiate excitement as an example for their students. There is nothing here in the middle, there are only we humans of different ages who share the pleasure of thinking about Totality in an ever more precise and humanizing way. If the teacher does not experience the emotional moment of the creative act of thinking every day at school, no student will begin to think. At the table, the awareness of being there is perceptible, of being there to paint the traits that define what it is to be human. Education listens. How to define a learning environment of this kind? Brian Eno coined the term scenius, a collective equivalent of genius. It refers to a research community in which you can think and in which you can feel the pleasure of having thought. The school changes from just a place to a beautiful inner landscape, to the extent that it makes possible the act of thinking, and this can be achieved only by placing emptiness in the architectural center. All you need is a blueprint for thought.

The third architectural level on which $\mathrm{BH} 678$ acts is the curricular, didactic one. The empty space requires an allure, a blueprint for thought. Look at the Farnsworth House, designed by Ludwig Mies van der Rohe; here is our guide for thought. Beams and pillars are the Languages: L1 grammar, then L2 and L3, and Mathematical Language (including technical drawing). The large glass walls are a unique cultural corpus called BIG
HISTORY. The languages represent a gym for the development of knowledge and skills, while Big History is configured as the big stage on which knowledge and skills are transformed into competencies by entering a complex global tableau. Big History is an approach to knowledge that embraces the entire universal history in one single

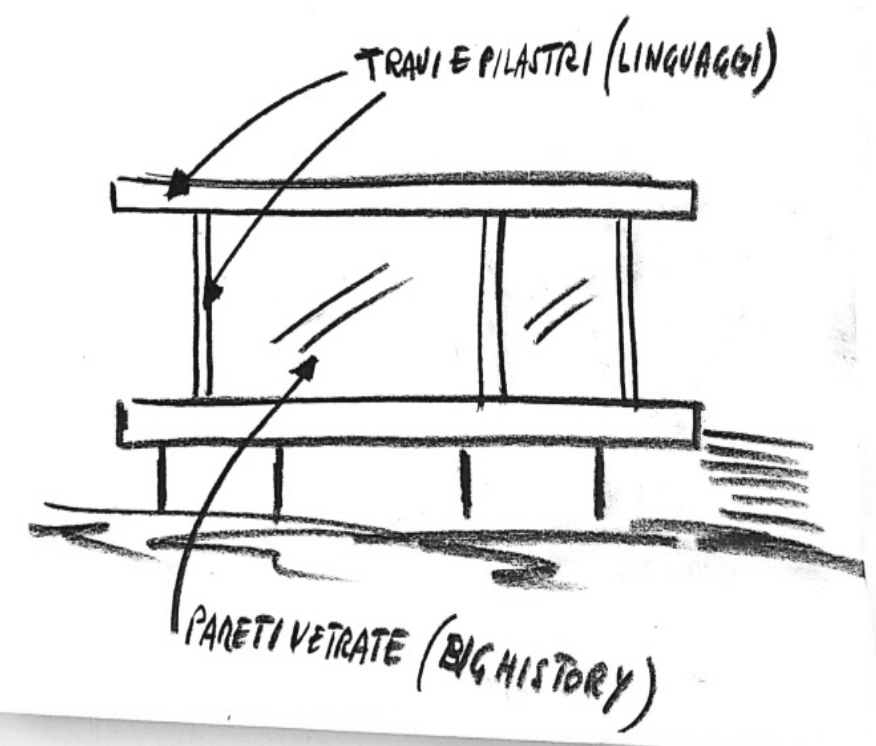

Figure 3. Thought

course, from the beginning of the universe's expansion to the future. The course follows the increase in the global complexity of the universe itself and rotates progressively through the various disciplines, which act as tools, narrating voices in order to tell parts of this long, united story. The path covers approximately 13.8 billion years, and this forces the cultural explorer to identify some threshold moments in which to create stages to reflect on distinct portions of the story. The thresholds were chosen because they coincide with a significant increase in the general complexity. The course, created by Professor David Christian, envisages ten threshold and is typically proposed in schools and universities as an independent discipline, in addition to the existing curriculum or integrated into it.

BH678 proposes, instead, for the first time, a Big History format tailored to the Italian middle school. In this case we are not talking about adding a subject matter, but about reformulating, reformatting the entire didactic curriculum on the basis of Big History, creating the empty space necessary to allow interaction and collaboration between the fragments of knowledge that are 
represented by the various disciplines already present in the school. In the $\mathrm{BH} 678$ version of Big History, the following disciplines will be involved: philosophy, the sciences, geography, history, L1 literature, classics, L2 and L3 languages with CLIL (Content and Language Integrated Learning) activities, technology, art, music, religion or an alternate subject. In light of the specificity of the needs of middle school students, BH678 adds to the classic Big History path three original preparatory thresholds, necessary for the progressive introduction of some intersecting themes, such as the encounter between reality, diversity and complexity. The articulation of the course, therefore, differs from tradition by providing in total the following thirteen thresholds in Table 1.

The nomenclature of the thresholds appears at first glance aligned with a purely scientific trajectory. In order to follow successfully the vision of BH678 as a framework for a renewed interdisciplinary educational curriculum in complexity, an interesting operation of respectful hybridization and vaporization of the nature of the thresholds has become necessary. From each threshold, key words have been extracted, capable of blurring the outlines of spaces for dialogue acces- sible to all the disciplines. These key words, common and consistent with the scientific story, yet permeable, were then re-inflected within each subject, which created ad hoc activities from them. From this is derived an outline structure for the curriculum that presents the thresholds as a chain of large pools of mysteries in which to immerse the students.

Around each threshold is proposed a cloud of activities defined as thought exercises, proposed by the different disciplinary areas, but referable to and inspired by the same threshold key words. Each pool is surrounded by its own cloud of thought exercises, and such clouds are infinitely implementable by the teaching community. An interesting feature of the clouds is that they allow for educational outings, events, and trips consistent with the complexity thresholds to be included among the activities. The system therefore calls for an entire plan of excursions that are favorable to Big History. When students enter the pool of mysteries represented by the threshold, they tackle common themes but study them from the different points of view offered by the various disciplines. The result is a total immersion in the true complex nature of a theme, savoring the

\begin{tabular}{|c|l|c|}
\hline THRESHOLD & \multicolumn{1}{|c|}{ OUTER MOMENT } & INNER KEYWORD \\
\hline $00 \mathrm{~A}$ & Encounter with Reality & From Signs to Symbols \\
\hline $00 \mathrm{~B}$ & Diversity & Mames \\
\hline $00 \mathrm{C}$ & Complexity & Darkness \\
\hline 01 & $\begin{array}{l}\text { Origin of the universe (space, time, } \\
\text { matter and energy }\end{array}$ & Light \\
\hline 02 & Origin of stars and galaxies & Colours \\
\hline 03 & Origin of the new chemical elements \\
\hline 04 & Origin of the Sun and the solar system & Information and Soul \\
\hline 05 & Origin and evolution of life & Human spirit \\
\hline 06 & Human origin and evolution & $\begin{array}{c}\text { Voices of the human spirit } \\
\text { (from Neolithic to Middle } \\
\text { Ages) }\end{array}$ \\
\hline 07 & $\begin{array}{l}\text { Domestication (of animals and plants), } \\
\text { cities, states, agricultural civilizations } \\
\text { and their evolution }\end{array}$ & $\begin{array}{c}\text { Voices of the human spirit } \\
\text { (Modern Age) }\end{array}$ \\
\hline 08 & $\begin{array}{l}\text { Expansion and connection: towards } \\
\text { modernity }\end{array}$ & $\begin{array}{c}\text { Voices of the human spirit } \\
\text { (Contemporary Age) }\end{array}$ \\
\hline 09 & Acceleration and Anthropocene & Renewed human spirit \\
\hline 10 & The future & \\
\hline
\end{tabular}


organic uniqueness of the human ability to gather connections, which is obscured by the linear thought that is traditionally taught. Turning to metaphorical and symbolic interpretation practices as well, the holistic approach to the thresholds creates the conditions for a definitive inclusive essence of the $\mathrm{BH} 678$ curriculum. Consistent with what is expressed about the importance of a scenius centered on Homo sapiens, the results of inclusiveness strike both teachers and students.

\section{BH678}

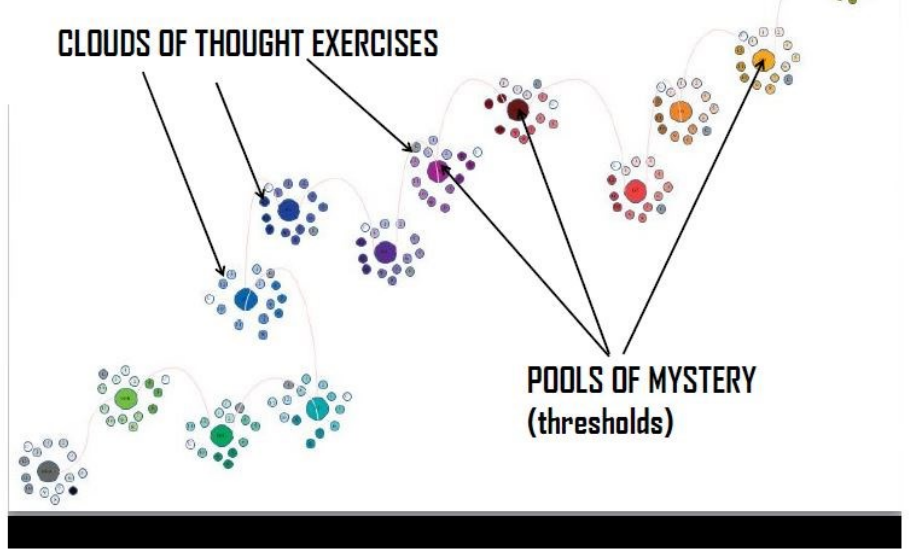

Figure 4 BH678

Teachers are guaranteed the opportunity to create freely thought exercises and to choose which activities to offer their students from the various formations of clouds. On the other hand, students are offered the opportunity to follow their own inclinations, deepening the themes of each threshold through a modular quantity relative to the number of exercises coming from different disciplinary fields. In order to guide the teachers in the construction of thought exercises consistent with the thresholds, an activity sheet and a suggested lecture has been prepared, which serve as an introduction to each threshold of the educational path, while awaiting the composition of a textbook dedicated to $\mathrm{BH} 678$.

Following the $\mathrm{BH} 678$ path, outlined by the pools of mysteries, we realize that the topics dealt with are usually part of the normal list of contents provided for by the National Guidelines. The BH678 ecosystem eliminates redundancies, and thanks to a collective and holistic assembly, finally manages to put into dialogue the brushstrokes of knowledge, which otherwise would be destined to remain prisoners of their nature of slavery to fragmentation.

Welcome, skyscraper-Homo sapiens. Without your boundless vital desire, nothing of BH678 would be possible. So sit at this table, and let's breathe together. I've been waiting for you.

\section{References}

Christian, David. 2005. Maps of Time: An Introduction to Big History. Oakland: University of California Press.

---. 2018. Origin Story: A Big History of Everything. New York: Little, Brown and Company.

Christian David, Cynthia Stokes Brown, and Craig Benjamin. 2014. Big History: Between Nothing and Everything. New York: McGraw-Hill Education.

DK, 2016. Big History: Our Incredible Journey, from Big Bang to Now. London: Dorling Kindersley.

Montessori, Maria. 1946. Education for a New World. 1989. Oxford, England: Clio Press.

---. 1948. To Educate the Human Potential. 1989. Oxford, England: Clio Press.

---. 1973. From Childhood to Adolescence. 1996. Oxford, England: Clio Press.

Rothko, Mark. 2002. Scritti. Milano: Abscondita Editore.

van der Rohe, Ludwig Mies. 2010. Gli scritti e le parole. Torino: Einaudi Editore. 